\section{Mephentermine: rediscovering its biology and use, misuse and their implications}

\section{Mefentermina: redescobrindo sua biologia, uso, abuso e suas implicações}

\section{Dear Editor,}

Mephentermine is an amphetamine-derived phenethylamine which shares a strong chemical similarity with both methamphetamine and the resulting stimulant actions of the alpha and beta adrenoceptors. It has been proposed that phentermine, which is a main metabolite of mephentermine, acts by inhibiting monoaminoxidases A and B. ${ }^{1}$

Mephentermine is less powerful compared to methamphetamine, and was traditionally used as a vasoconstrictor to maintain blood pressure in cases of hypotension during spinal anesthesia in patients undergoing elective Caesarean section procedures and pregnancy. ${ }^{2}$ It has also been used as a nasal decongestant. ${ }^{3}$

Nowadays, it is mainly used as a stimulant administered to disease-recovering competition animals. Its misuse by humans to achieve better physical performance has been described, however little data is available on the dependence and misuse of mephentermine. ${ }^{4}$

Both mephentermine and phentermine are stimulants whose use is prohibited by the World Anti-Doping Agency (WADA). ${ }^{1}$

Only five case reports on the misuse and or dependence of mephentermine were found in the literature. The first two cases involved the misuse of mephentermine without dependence secondary to the use of inhalers. This misuse induced acute paranoid-hallucinatory symptoms that were identical to those seen in amphetamine-caused psychosis or acute paranoid schizophrenia. The third case involved a patient who became dependent although this patient had already presented psychotic symptoms on prior occasions. The fourth case involved an associated dependence of mephentermine, buprenorphine and promethazine. ${ }^{3,4}$

In Brazil, the use of mephentermine is restricted to veterinary use. It is used for fatigue, anemia, malnutrition and recovery from infectious and parasitic diseases. Its commercial names are Potenay ${ }^{\circledR}$ and Potemax ${ }^{\circledR}$, which are administered orally or injected intramuscularly. The recommended dose for horses, cattle, swine, goats, dogs and cats is 6 to $12 \mathrm{mg}$ for each $5 \mathrm{~kg}$ twice or three times a day.

Our group has recently described the sixth case of misuse and the second case of mephentermine dependence without the presence of psychotic symptoms in a 22-year-old Brazilian man. The same case is the first described in Brazil. Although our initial experience with this patient revealed that this substance is widely available for sale in the black market, the medical literature has not yet fully investigated enough cases on the misuse of mephentermine and its derivates. ${ }^{4}$

Our aim is to highlight the relevance of a theme that is certainly more frequent than what is shown by the data currently available and is associated with social issues. The misuse of mephentermine can bring about major clinical implications, which may include secondary hypertension and a myriad of cardiovascular diseases such as arrhythmias and sudden death syndrome.

The extensive use of these substances may warrant testing for these drugs on a more routine basis by drug monitoring programs. The healthcare community should, by all means, conduct surveys to identify new kinds of stimulants that are used to generate intellectual and physical doping. ${ }^{5}$

Furthermore, we support the establishment of a public health program whose goal would be to disseminate information about the risks involved to both users and non-users, as well as to provide specific treatment to already dependent patients and appropriate training to human resources so as to better prepare them to deal with these cases.

Matheus Fernandes de Oliveira

Department of Neuropsychiatry, Universidade Federal de Pernambuco (UFPE), Recife, PE, Brazil

Hospital do Servidor Público Estadual de São Paulo (FMO), São Paulo, SP, Brazil

Henrique Faria de Sousa, Murilo Costa Duarte Lima, João Ricardo Mendes de Oliveira Department of Neuropsychiatry, Universidade Federal de Pernambuco (UFPE), Recife, PE, Brazil 


\begin{tabular}{|c|c|c|c|c|c|c|c|}
\hline $\begin{array}{l}\text { Writing group } \\
\text { member }\end{array}$ & Employment & $\begin{array}{l}\text { Research } \\
\text { grant }^{1}\end{array}$ & $\begin{array}{l}\text { Other research } \\
\text { grant or medical } \\
\text { continuous } \\
\text { education }\end{array}$ & Speaker's honoraria & $\begin{array}{l}\text { Ownership } \\
\text { interest }\end{array}$ & $\begin{array}{l}\text { Consultant/ } \\
\text { Advisory } \\
\text { board }\end{array}$ & Other $^{3}$ \\
\hline $\begin{array}{l}\text { Matheus } \\
\text { Fernandes de } \\
\text { Oliveira }\end{array}$ & UFPE & - & - & - & - & - & - \\
\hline $\begin{array}{l}\text { Henrique Faria } \\
\text { de Sousa }\end{array}$ & UFPE & - & - & - & - & - & - \\
\hline $\begin{array}{l}\text { Murilo Costa } \\
\text { Duarte Lima }\end{array}$ & UFPE & - & - & - & - & - & - \\
\hline $\begin{array}{l}\text { João Ricardo } \\
\text { Mendes de } \\
\text { Oliveira }\end{array}$ & UFPE & - & - & - & - & - & - \\
\hline \multicolumn{8}{|c|}{ 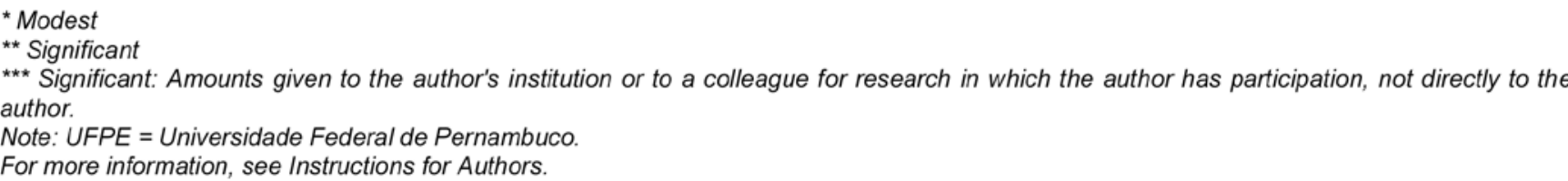 } \\
\hline
\end{tabular}

References

1. Docherty JR. Pharmacology of stimulants phohibited by the World Anti-Doping Agency (WADA). Br J Pharmacol. 2008;154(3):606-22.

2. Kansal A, Mohta M, Sethi AK, Tyagi A, Kumar P. Randomised trial of intravenous infusion of ephedrine or mephentermine for management of hypotension during spinal anaesthesia for Caesarean section. Anaesthesia. 2005;60(1):28-34.

\section{Quality of life and depressive symptoms in Parkinson's disease}

\section{Qualidade de vida e sintomas depressivos na doença de Parkinson}

\section{Dear Editor,}

Depression is the most common psychiatric comorbidity in Parkinson's disease (PD) and can affect up to $68.1 \%$ of patients with this movement disorder. ${ }^{1}$ It is well-known that depression directly affects the quality of life and psychosocial functioning of $\mathrm{PD}$ patients. Thus, we have read with great interest the article by Margis et al. in which the authors assessed the influence of depressive symptoms on the quality of life of PD patients. ${ }^{2}$ The authors observed that the Geriatric Depression Scale (GDS) score was positively associated with the total score in the World Health Organization Quality of Life Assessment for older adults and five of its six domains.

To the same end as Margis et al., ${ }^{2}$ we have recently used the 39item Parkinson's Disease Questionnaire (PDQ-39) and its eight dimensions and the 15-item GDS (GDS-15) to assess quality of life and depressive symptoms in PD patients, respectively. We divided the patients into two groups (PD without depression and
3. Basu D, Nebhinani N. Mephentermine dependence without psychosis. Indian J Med Sci. 2009;63(3):117-9.

4. Sousa HF, Oliveira MF, Costa Lima MD, Oliveira JR. Mephentermine dependence without psychosis: a Brazilian case report. Addiction. 2010;105(6):1129-30.

5. Oliveira JR. Much ado about cognitive enhancement. Nature. 2009;457(7229):532.

PD with depression) according to the GDS-15 cutoff score of eight proposed for the screening of depression in PD. ${ }^{3}$

The study was approved by the local ethics committee and the patients gave their informed consent to participate (HCRP $\mathrm{n}^{\circ}$ 10078/2009).

A total of 114 patients ( $50.9 \%$ male) with a mean age of 64.7 years $(\mathrm{SD}= \pm 12.6)$ were enrolled. Most participants $(\mathrm{n}=92$; $80.7 \%$ ) had little education (less than 8 years), were not working $(\mathrm{n}=109 ; 95.6 \%)$, and were married $(\mathrm{n}=65 ; 57 \%)$. One limitation of this study is the absence of further clinical data. In addition, structured clinical interviews (e.g.: SCID-CV) were not applied for the diagnosis of depression. This is also a limitation of the study by Margis et al. ${ }^{2}$

The total score in the PDQ-39 and its subscales/dimensions strongly correlated with the total score in the GDS-15. The group of patients with current depression (GDS-15 $\geq 8$ ) had higher scores $(\mathrm{p}<0.0001)$ in the PDQ-39 and its dimensions (Table 1). Therefore, our findings confirm and expand the results found by Margis et al. ${ }^{2}$

Nowadays, special attention has been given to the non-motor symptoms of PD in clinical and research settings. In particular, depressive symptoms have been consistently associated with poor quality of life, and, in some studies, this correlation is stronger than that found for motor symptoms. ${ }^{4}$

The mobility dimension was strongly correlated with depressive symptoms ( $r$ o $=0.654$ ) in our study. This is in line with the findings of Margis et al., ${ }^{2}$ in which depression 